ARTICLE

DOI: $10.1038 / s 41467-018-06803-z$

\title{
3D virtual reconstruction of the Kebara 2 Neandertal thorax
}

\author{
Asier Gómez-Olivencia ${ }^{1,2,3,4}$, Alon Barash ${ }^{5}$, Daniel García-Martínez ${ }^{6}$, Mikel Arlegi ${ }^{1,7}$, Patricia Kramer ${ }^{8}$, \\ Markus Bastir (D) ${ }^{6}$ \& Ella Been 9,10
}

The size and shape of the Neandertal thorax has been debated since the first discovery of Neandertal ribs more than 150 years ago, with workers proposing different interpretations ranging from a Neandertal thoracic morphology that is indistinguishable from modern humans, to one that was significantly different from them. Here, we provide a virtual 3D reconstruction of the thorax of the adult male Kebara 2 Neandertal. Our analyses reveal that the Kebara 2 thorax is significantly different but not larger from that of modern humans, wider in its lower segment, which parallels his wide bi-iliac breadth, and with a more invaginated vertebral column. Kinematic analyses show that rib cages that are wider in their lower segment produce greater overall size increments (respiratory capacity) during inspiration. We hypothesize that Neandertals may have had a subtle, but somewhat different breathing mechanism compared to modern humans.

\footnotetext{
${ }^{1}$ Dept. Estratigrafía y Paleontología, Facultad de Ciencia y Tecnología, Universidad del País Vasco/Euskal Herriko Unibertsitatea (UPV/EHU), Barrio Sarriena s/n, 48940 Leioa, Spain. ${ }^{2}$ IKERBASQUE. Basque Foundation for Science, 48013 Bilbao, Spain. ${ }^{3}$ Équipe de Paléontologie Humaine, UMR 7194 , CNRS, Département de Préhistoire, Muséum National d'Histoire naturelle, Musée de I'Homme, 17, Place du Trocadéro, 75016 Paris, France. ${ }^{4}$ Centro Mixto UCMISCIII de Evolución y Comportamiento Humanos, Avda. Monforte de Lemos, 5, Madrid 28029, Spain. ${ }^{5}$ Faculty of Medicine in the Galilee, Bar-Ilan University, Henrietta Szold, 8. P.O.B 1589, 1311502 Zefat, Israel. ${ }^{6}$ Paleoanthropology Group, Museo Nacional de Ciencias Naturales (CSIC), J. G. Abascal 2, 28006 Madrid, Spain. ${ }^{7}$ Université de Bordeaux, Allée Geoffroy Saint-Hilaire, PACEA UMR 5199, Bâtiment B8, 33615 Pessac, France. ${ }^{8}$ Departments of Anthropology and Orthopaedics and Sports Medicine, University of Washington, Seattle, WA 98195-3100, USA. ${ }^{9}$ Department of Sports Therapy, Faculty of Health Professions, Ono Academic College, 5545001 Kiryat Ono, Israel. ${ }^{10}$ Department of Anatomy and Anthropology, Sackler Faculty of Medicine, Tel Aviv University, 6997801 Tel Aviv, Israel. These authors contributed equally: Asier Gómez-Olivencia, Ella Been. Correspondence and requests for materials should be addressed to A.Góm-O. (email: asier.gomezo@ehu.eus)
} 
T he study of the evolution of the human thorax is paramount to understanding key aspects of human paleobiology. The thorax is the insertion point of muscles related to the movement of the upper limb, connects the latter to the trunk ${ }^{1}$, and protects important organs of the chest. The general size of the thorax of organisms has been correlated with their total lung capacity, an important physiological variable ${ }^{2-4}$. The costal skeleton and the spine, which provide important clues for understanding locomotion and posture ${ }^{5-7}$, are interdependent. The study of the thorax is hampered, however, by the intrinsic difficulties of studying metameric elements, the fragility of both ribs and vertebrae and their scarcity in the fossil record ${ }^{8-10}$.

The size and shape of the Neandertal thorax has been a subject of scientific debate for more than 150 years. Fuhlrott ${ }^{11}$ described the costal remains belonging to the Feldhofer 1 Neandertal individual found in 1856 as having a circular cross-section and a low degree of curvature. Similar anatomical features were proposed for the fossils found in Spy (Belgium) $)^{12}$, Krapina (Croatia) $^{13}$, and La Chapelle-aux-Saints 1 (France) ${ }^{14}$. GorjanovićKramberger ${ }^{13}$ suggested a dorso-ventrally expanded thorax based on the low degree of curvature of the first ribs of Krapina, which was also proposed based on the conoid length of the Neandertal clavicles $^{15}$. The thorax of the Tabun $\mathrm{C} 1$ female Neandertal skeleton was estimated to be large (relative to stature) with very curved and more horizontally oriented ribs than modern humans ${ }^{16}$. However, other studies proposed that Neandertal ribs were very similar to that of modern populations ${ }^{17}$ or just observed that Neandertal ribs were more robust, but were not, on their own, evidence for a more voluminous thorax compared to modern humans ${ }^{18}$. The reassessments of the costal skeletons of Shanidar $3^{8}$, Kebara $2(\mathrm{~K} 2)^{9}, 10$, La Chapelle-aux-Saints $1^{19}$, and the description of new Neandertal costal remains, from the site of El Sidrón ${ }^{20,21}$ and Regourdou $1^{22}$ individual provide new information. Additionally, the implementation of 3D geometric morphometric techniques to these studies helps to quantify differences between the modern human and Neandertal thorax ${ }^{10,20,21,23}$.

The larger costal skeleton in Neandertals, with longer midthoracic ribs than modern humans, was hypothesized to result in a more voluminous thorax. This larger thoracic volume could have been related to a need for more oxygen intake due to their larger body masses and hunter-gatherer life-style ${ }^{4,8,24}$, and an exaptation for cold-climate conditions ${ }^{9}$. The larger Neandertal costal skeleton, especially the longer mid-thoracic ribs, has also been linked to longer mesosterna ${ }^{25}$. The presence of less-curved first ribs has been confirmed in Neandertals and has been linked to shape differences in the upper thorax ${ }^{20-22}$. Finally, the more dorsally oriented transverse processes in the mid-thoracic spine has been related to a larger degree of invagination of the spine within the thorax ${ }^{26}$. All the proposals relative to the general size and shape of the Neandertal thorax were derived from an analytic approach based mainly on isolated skeletal specimens, pointing towards important differences between the Neandertal thorax and that of modern humans.

To our knowledge, only one study has approached the problem of the size and shape of the Neandertal thorax from a synthetic approach. Within the context of the reconstruction of a complete Neandertal skeleton, skeletal elements from La Ferrassie 1 were combined with other Neandertal individuals, including the thoracic and lumbar spine and costal skeleton of $\mathrm{K}^{27}$. The first two ribs of K2 were elongated in order to fit the thorax to the longer clavicles and generally larger La Ferrassie 1 body frame ${ }^{27}$. Sawyer and Maley ${ }^{27}$ also indicated the presence of flaring lower thorax which resulted in what they called a "bell-shaped thoracic region". More recent studies have provided important morphological information regarding the spinal morphology of
Neandertals which has resulted in an interpretative shift regarding Neandertal posture $6,7,28-31$. Additionally, errors in the reconstruction of the $\mathrm{K} 2$ ribs have been documented ${ }^{9}, 10$, which could have affected the previous reconstruction of this thorax.

Here we present the 3D virtual reconstruction of the most complete adult Neandertal thorax found to date, that of the K2 individual. The cave site of Kebara is located on Mount Carmel, $13 \mathrm{~km}$ south of Wadi el Mughara ${ }^{32}$. This site has yielded two partial Neandertal skeletons: the 8-9 month infant Kebara $1^{33}$ and the adult $\mathrm{K} 2^{34}$, as well as other isolated Neandertal remains ${ }^{35}$. The burial of K2 was found in 1983 in level XII ${ }^{36}$, which is dated by thermoluminiscence in $60 \pm 3.5 \mathrm{ky}^{37}$. The skeleton preserves the mandible, an upper third molar, the hyoid, the scapular girdle and the upper limb, the pelvic girdle, the proximal half of the left femur, and the most complete Neandertal vertebral column and thorax found to date ${ }^{34,36}$ (Supplementary Figs. 1-5). The average age-at-death of K2 based on different methods is 32 years $^{38}$. K2 has been determined to be male based on pelvic morphology 36,39 and his stature was estimated between $168.7^{40}$ and $170.3 \mathrm{~cm}^{6}$. His body mass was estimated at $75.6 \mathrm{~kg}^{41}$. The skeleton of $\mathrm{K} 2$ shows several anomalies and/or pathological lesions including the presence intercostal ossifications and pseudoarthroses in ribs 5-7 from the right side ${ }^{42}$. Recent research has, however, ruled out previous hypotheses, pointing out that the apophyses and nearthrosis observed in the ribs are caused by a genetically driven anatomical variant ${ }^{43}$, and there is no evidence to assume that this anatomical variant implies any functional constraint in the ribcage. We have also detected the presence of a slight scoliosis, which did not reach a pathological level ${ }^{6}$. The 3D virtual reconstruction of the K2 thorax provides a comprehensive context for the differences found in the isolated vertebrae and ribs of Neandertals when compared to modern humans. With this reconstruction, we are able to perform a comparative morphometric analysis of the K2 thorax which indicates that the differences in vertebrae and ribs result in differences in the thorax as a whole between modern humans and Neandertals. We also discuss these differences of the thorax in relationship to the Neandertal lumbo-pelvic complex and its evolutionary implications. This virtual reconstruction of an extinct hominin trunk reveals the interdependence of the pelvic morphology, the spine, and the costal skeleton.

\section{Results}

Size and shape of the 3D reconstruction of the Kebara 2 thorax. The 3D virtual reconstruction of the Kebara 2 Neandertal trunk is shown in Fig. 1. Measurements of the thorax of Kebara 2 compared to our modern male sample are shown in Table 1. Kebara shows a mild (i.e., $<20^{\circ}$ ) scoliosis ${ }^{6}$ and a genetically driven anatomical variant in ribs 5-7 from the right side ${ }^{42,43}$. We compared our 3D reconstruction of the K2 thorax to the mean shape of our modern male sample. In order to facilitate the visualization of this comparison, a modern thorax was warped into the K2 shape and then superimposed to the modern male mean (Fig. 2). In cranial view, the most striking feature is the invagination of the thoracic spine into the K2 thorax: in K2 the dorsal-most tips of the spinous processes are embedded within the limits defined by the dorsal surfaces of the posterior angles of the ribs, while in modern humans these tips project more dorsally. This invagination is consistent with previous suggestions based on the orientation of the transverse processes of the thoracic vertebrae ${ }^{26}$ (Supplementary Note 1).

In ventral view, when compared to modern humans, K2 shows a wider mid-lower thorax (mainly around ribs 6-9). This is in accordance with the maximum width of the thorax, which is larger in our reconstruction than in our modern male 
comparative sample (Table 1). In lateral view, the ribs of $\mathrm{K} 2$ show a more horizontal orientation, which results in a slightly more antero-posteriorly deep thorax (Table 1). In this view, it is also possible to see the less marked kyphosis of the thoracic spine ${ }^{6}$. We should note that, despite not being significantly different, K2 shows a cranio-caudally shorter thorax than our modern human comparative sample (Table 1).

The geometric morphometric analyses of the whole thorax in shape space $^{44}$ (Fig. 3; Supplementary Figs. 8, 9), i.e., without the influence of size, demonstrates that the thorax morphology of the K2 individual falls outside modern human variability when we plot PC2 against PC3 (Fig. 3). These differences were confirmed using a permutation test: $\mathrm{K} 2$ is significantly different from the modern human male mean (Procrustes distance $=0.1098$; $p<$

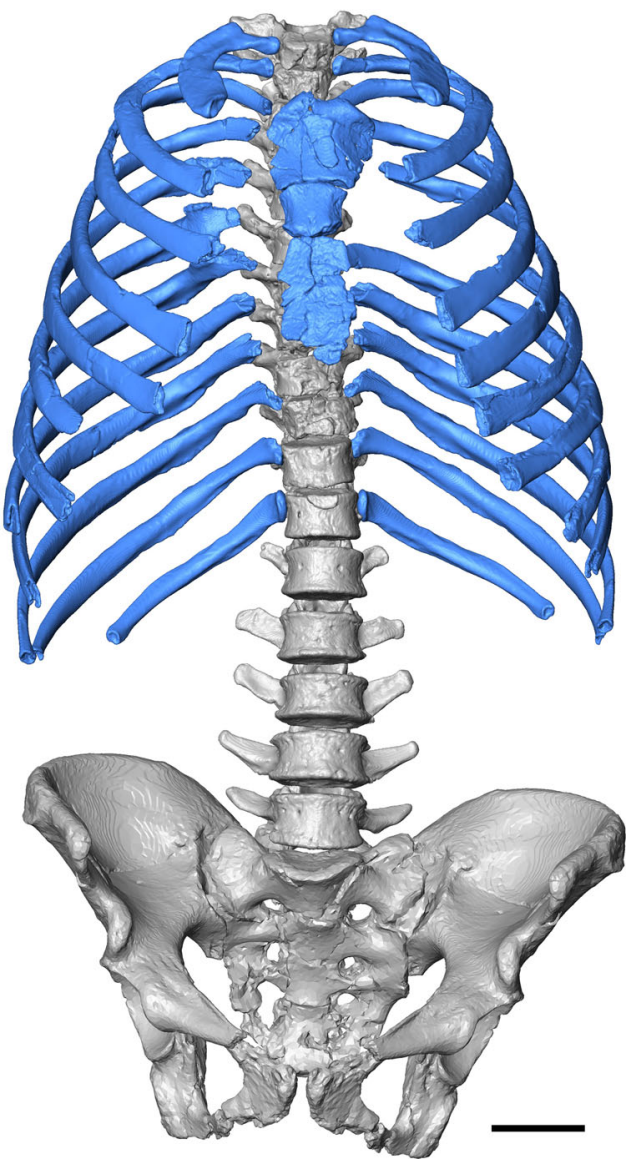

Fig. 1 Ventral view of the reconstructed thorax of Kebara 2. The blue color is to highlight the ribs and the sternum. Scale bar $=5 \mathrm{~cm}$
0.01). These morphological differences are mainly related to the wider mid-lower thorax of $\mathrm{K} 2$ compared to that of modern human sample.

Finally, despite the differences found in the width and depth of the K2 thorax (Table 1), the overall size (based on the centroid size) of the $\mathrm{K} 2$ reconstructed thorax is similar to that of the modern human comparative sample (Table 1). This results from the shorter cranio-caudal dimension of the thorax and from the deeper invagination of the vertebral bodies in $\mathrm{K} 2$, when compared to modern humans. In summary, our reconstruction of the K2 thorax shows that, when compared to modern human males of similar stature (using thorax height and humeral maximum length as a predictor of stature), this individual showed a significantly wider mid-lower thorax which was slightly larger dorso-ventrally. Additionally, our reconstruction shows that the thoracic spine was invaginated within the K2 thorax to a larger degree than in modern humans and that his ribs were more horizontally oriented. Despite these significant morphological differences, the thorax of Kebara 2 was not significantly larger than that of modern humans.

\section{Discussion}

Here we provide the accurate reconstruction of the most complete adult Neandertal thorax found to date: that of Kebara 2. Our reconstruction shows significant metric and morphological differences when compared to modern human males of similar stature. These differences can be explained by differences in the morphology of the thoracic spine, the costal skeleton, and the interplay between these two anatomical regions. Further, we hypothesize that the pattern shown by the K2 reconstruction can be extended to other Neandertals for two reasons: first, the restricted hypodigm of Neandertal mid- and lower thoracic vertebrae shows more dorsally oriented transverse processes, evidence for a more invaginated spine ${ }^{26}$ (Supplementary Note 1); and second, all the Neandertal individuals on which it has been possible to perform metric comparative analyses of their costal skeleton, show the same metric and/or morphological differences with modern humans ${ }^{8-10,19-22}$

The size of the Neandertal thorax has been a matter of debate due not only to its relationship to the general skeletal structure, but also due to its relationship to the total lung capacity ${ }^{4,24}$. Previous studies have emphasized the larger size of the $\mathrm{K} 2$ costal skeleton based on the longer ribs of the mid-thorax ${ }^{9,10}$. In this study, we provide evidence of a larger degree of invagination of the vertebral column into the thorax in Kebara 2. We consider that some of the differences observable in the Neandertal costal skeleton, such as a longer distance between the tubercle and the posterior angle, is related to this invagination. The posterior angle marks the insertion point of the erector spinae muscles, and a

\begin{tabular}{|c|c|c|c|c|c|c|c|c|c|}
\hline & Sex & $\begin{array}{l}\text { Age/age- } \\
\text { at-death }\end{array}$ & $\begin{array}{l}\text { Full thorax } \\
\text { CS }\end{array}$ & $\begin{array}{l}\text { Maximum } \\
\text { thorax } \\
\text { width (mm) }\end{array}$ & $\begin{array}{l}\text { Thorax } \\
\text { deptha }^{\mathrm{a}} \\
(\mathrm{mm})\end{array}$ & $\begin{array}{l}\text { Thorax } \\
\text { heightb }^{\circ} \\
(\mathbf{m m})\end{array}$ & $\begin{array}{l}\text { Humeral } \\
\text { length } \\
(\mathbf{m m})\end{array}$ & $\begin{array}{l}\text { Stature estimation } \\
(\mathrm{cm})\end{array}$ & $\begin{array}{l}\text { Bi-iliac breadth } \\
(\mathrm{mm})\end{array}$ \\
\hline & Male & $25-39^{38}$ & 3281.19 & $326.8^{d}$ & 224 & 265.5 & $\begin{array}{l}317(R) / 324 \\
(L)^{e}\end{array}$ & 165.45 & $319.7^{d} / 313^{52, d}$ \\
\hline $\begin{array}{l}\text { Homo } \\
\text { sapiens }\end{array}$ & $\begin{array}{l}\text { Males } \\
(n=16)\end{array}$ & $70.63 \pm 10.04$ & $\begin{array}{l}3303.95 \pm \\
112.47\end{array}$ & $\begin{array}{l}298.16 \pm \\
13.87\end{array}$ & $\begin{array}{l}217.54 \pm \\
13.95\end{array}$ & $\begin{array}{l}282.85 \pm \\
19.38\end{array}$ & $\begin{array}{l}320.34 \pm \\
12.38 \\
(n=14)\end{array}$ & $\begin{array}{l}167.00 \pm 5.72 \\
(n=14)\end{array}$ & $284.13 \pm 12.15$ \\
\hline
\end{tabular}



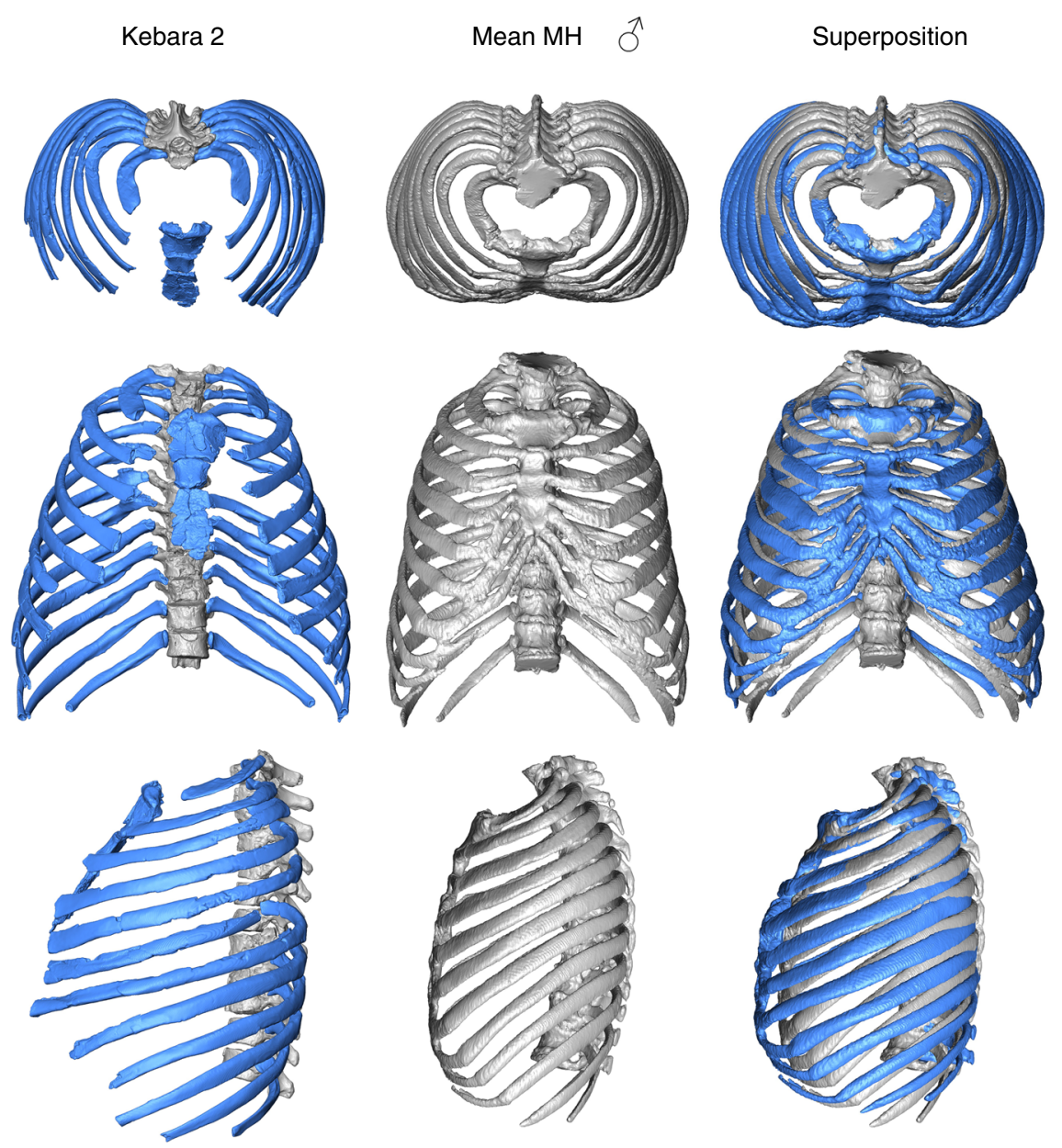

Fig. 2 Comparison of the Kebara 2 (K2) thorax (left column; see legend in Fig. 1 for color explanation) to the modern human male sample (in gray; middle column) and superposition of the two morphologies (in blue, Kebara 2; in gray, the modern human sample male mean; right column) in cranial (top row), ventral (middle row) and left lateral (lower row) views. In the cranial view, the invagination of the K2 spine into its thorax is noticeable. In ventral view, the relatively (and absolutely; see Table 1) wider thorax of Kebara 2 compared to modern humans is appreciable. In lateral view, K2 shows relatively larger antero-posterior mid-thorax and straighter shafts of the rib, while modern humans show more caudally curved ribs sternal to the posterior angle. In the third column the same template has been used in order to represent the modern human male mean (gray) and the K2 morphology. In the superposition, both the modern human male thorax and the $\mathrm{K} 2$ thorax scaled to the same centroid size

more invaginated thoracic spine would require not only more dorsally oriented transverse processes, but also longer shafts in the segment between the posterior angle and the tubercle of the ribs ${ }^{9}$. While this would result in an absolutely longer rib, which is the case of the K2 mid-thoracic ribs ${ }^{9,10}$, it does not affect to the overall size of the thorax. This is due to the fact that the general size of the thorax is an interplay of not only the size of the costal skeleton, but also its articulation with the spine ${ }^{21}$.

Despite the calculated larger energy expenditure of Neandertals ${ }^{4,24}$, which was previously proposed as consistent with their larger total lung capacities, our reconstruction does not show a larger skeletal thorax. In some high altitude human populations, an association between ventilatory capacities and thoracic dimensions exists ${ }^{4,15}$. Bellemare et al. ${ }^{3}$ indicated, however, that the size of soft tissues provides a better correlate to the lung ventilatory capacities than skeletal measurements, such as the antero-posterior and mediolateral diameters of the thorax. Based on the skeletal morphology, we cannot rule out that the total lung capacity of Neandertals was not different from that of modern humans. Differences in the soft tissues (such as height of the diaphragm) $)^{3}$ could, however, have resulted in a larger total lung capacity in Neandertals than in modern humans, despite a thorax of overall similar size.
Based on the relationship between the conoid length of the clavicle and the chord of the second rib, Neandertals have an antero-posteriorly expanded thorax ${ }^{15}$. Our K2 thorax reconstruction is slightly more expanded antero-posteriorly than the male comparative sample, although this difference is not significant. Other Neandertal individuals, normally considered as males, or of similar general size to $\mathrm{K} 2$, show longer and straighter first ribs (e.g., Regourdou 1 or the partially preserved Amud 1 $)^{9,22}$. Thus, it would not be surprising if other Neandertals had larger thoraces in the antero-posterior dimension. In fact, the less-curved first ribs in Neandertals, independently of their absolute size, have been related, through a 2-block partial least squares (PLS) analysis of the first ribs and the rest of the ribcage, to relatively wider thorax in its mid-lower part and to more horizontally oriented ribs in lateral view ${ }^{20}$. This accords with our K2 thorax reconstruction. In the case of Neandertals, this wider, in absolute terms, mid-lower thorax (already noted in a previous reconstruction $)^{27}$, would be consistent with the presence of wider pelves in Neandertals compared to modern humans ${ }^{45,46}$ (Table 1).

The increase in lung volume during inhalation is mainly related to two mechanisms: diaphragm flattening and the "bucket-handle" and "pump-handle" movements of the ribs ${ }^{1}$. In 

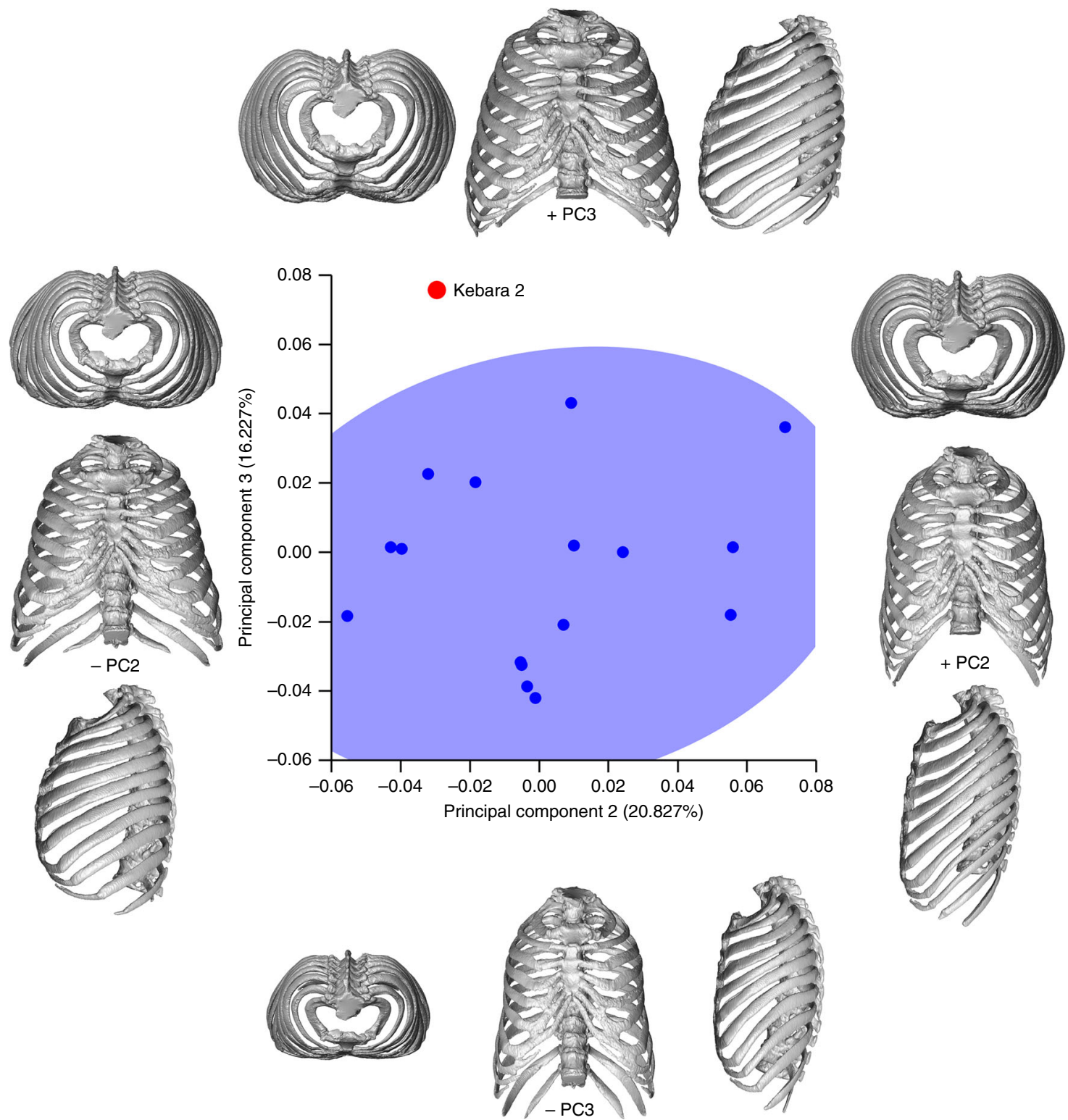

Fig. 3 Principal component analysis (PCA) representing the second (PC2) and third (PC3) principal components, which represent the 20.827\% and the $16.227 \%$ of the variation, respectively. In this plot Kebara 2 is outside the $95 \%$ of the equiprobability ellipse representing the modern human sample

ribs $1-7$, it seems that the "bucket-handle" and "pump-handle" movement of the ribs occur similarly in each level ${ }^{47}$, but the "bucket-handle" movement seems to predominate in the lower thorax. Despite similarities in the overall thoracic (centroid) size, K2 likely had a larger surface of the diaphragm due to the significantly larger mediolateral and slightly larger antero-posterior diameters of the lower thorax. On the one hand, the position of the diaphragm was likely a major factor to determine the total lung capacity of Neandertals (as discussed above), but additionally, its larger surface, due to the larger cross-section of the lower thorax, could have enhanced the ability to increase and decrease the total lung volume during breathing. In modern humans, the enlargement of the lower part of the ribcage, i.e., the area that supports the diaphragm, increases considerably the respiratory capacity $^{48}$. In fact a lung volume of about 9.041 has been calculated for the Kebara 2 individual based on the relationship between total lung capacity and costal arc length ${ }^{49}$.

On the other hand, in lateral view, the K2 reconstruction shows more horizontal ribs than is seen in modern humans. This likely constrained the rib elevation in the sagittal plane, which is related to the bucket-handle movements of the ribs. The larger articular tubercles of the lower ribs of Neandertals when compared to modern humans ${ }^{8,21,22}$, could be related to strong breathing kinematics in the lower thorax, which could also be related to the function of the diaphragm. In fact, kinematic analyses show that rib cages wider in its lower segment produce greater overall size increments (respiratory capacity) during inspiration ${ }^{50}$. In summary, we hypothesize that Neandertals may have had a somewhat different breathing mechanism, one which relied relatively more on diaphragm contraction, than is exhibited in modern humans. Consideration of the potential differences between Neandertals and modern humans in hematologic and biochemistry that could potentially also significantly affect the respiratory physiology, as has been seen in different extant modern human groups ${ }^{51}$, is beyond the scope of this report.

To fully comprehend the Neandertal thorax anatomy, understanding its relationships with the adjacent anatomical regions is critical. The reconstructed thorax presented here allows us to 
understand the biomechanical implications of the observed differences in the Neandertal thoracic and lumbar spine and the individual differences that we have documented in the costal skeleton. We hypothesize that, in Neandertals, the orientation and position of the sacrum within the pelvis is not only responsible for (or, at least, related to) the lower degree of curvatures of the spine, but also explains the invaginated spine within the thorax. The Neandertal sacrum is more vertically oriented than in modern humans, which is connected to the lower degree of lumbar lordosis ${ }^{6,7,28,29,31}$. At the same time, the Neandertal sacrum is positioned more ventrally relative to the dorsal end of the iliac tuberosities of the pelvis, than that of modern humans $s^{52,53}$. The dorsal projection of the iliac tuberosities would mark the dorsal end of the trunk (encompassing the pelvis, spine, and costal skeleton). Thus, a relatively more ventral sacrum within the pelvis could result in the invagination of the spine within the thorax, which would also affect the orientation of the transverse processes of the thoracic vertebrae and the length of the rib shafts between the tubercle and the posterior angle in the mid-thoracic ribs ${ }^{9}$ (as discussed above). A more invaginated spine would reduce the inertia moments of the costal skeleton with regards to the spine. Moreover, the orientation of the lumbar transverse processes, which are more laterally and vertically oriented than in modern humans ${ }^{31,54}$, would provide advantage in mediolateral flexion (e.g., the action of M. quadratus lumborum), which would be useful to stabilize the larger inertia moments of the significantly wider lower thorax of Kebara 2. In parallel, the wider pelvis of Neandertals, when compared to modern humans, likely imposed developmental constraints to the lower part of the thora ${ }^{55}$. We hypothesize that the narrower lower thorax present in modern humans is likely a derived condition within genus Homo, which appeared with the emergence of narrower pelves in Homo sapiens ${ }^{56-59}$

Neandertals are significantly different from modern humans in all the spinal regions, and based on comparisons with earlier hominins, previous work has demonstrated that the distinctive features of Neandertals in the vertebral column and pelvis: e.g., lower pelvic incidence, more vertical sacra, lower degree of lumbar lordosis, and lateral orientation of the transverse processes in the mid-lumber vertebrae, are derived within genus

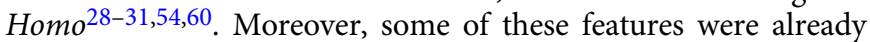
present in the Middle Pleistocene population from Sima de los Huesos $(\mathrm{SH})^{53,61}$. A relatively more ventral positioned sacrum was likely present in this Middle Pleistocene population (see Fig. 2 from Bonmatí et al. ${ }^{53}$ ) which would suggest that, in this population, the invagination of the spine seen in Kebara 2 was already present in the Middle Pleistocene populations ancestral to Neandertals. In the case of the costal skeleton, the only complete first rib from SH is larger than the largest complete Neandertal first rib (Regourdou 1$)^{22}$ and the SH hominins show wider pelves than Neandertals. Thus, it would be reasonable to expect larger thoraces in this population than that reconstructed here. The most complete first rib from SH seems, however, to be more curved than Neandertals ${ }^{62}$, which would be in accordance to the presence of some, but not all the Neandertal derived traits in this population ${ }^{61,63}$. Unfortunately, the lack of relatively complete Early Pleistocene adult costal remains and the immature status of the only Homo erectus costal skeleton (KNM-WT 15000) ${ }^{64,65}$ do not provide an evolutionary framework for the evolution of that thorax as complete as that present for the evolution of the vertebral column. In any case, we consider it likely that the modern human thorax morphology is also derived when compared to their Middle Pleistocene ancestral populations.

In summary, the present reconstruction demonstrates that subtle, but significant differences exist in the thorax shape within genus Homo. The thorax morphology seems to be the result of the interdependence of several features: general body size and pelvic and spinal morphology. While differences between upper and lower thorax exist ${ }^{23}$, some of the elements related to this interplay (and even within the same thorax) may change in a mosaic fashion $^{66}$. Additional fossils and more integration studies are necessary to provide additional evidence to understand the evolution of this anatomical region.

\section{Methods}

Fossil material. We have studied the original skeleton of Kebara 2 (K2; housed at Tel Aviv University) and have also used CT-scans of this individual. The scans of the vertebrae and ribs of this individual were made with a medical CT scan at Mount Carmel Medical Center, Haifa (voxel size: $0.598958 \times 598,958 \times 0.5 \mathrm{~mm}$ ), and the sacrum and coxal bones were scanned at Sheba Medical Center, Ramat Gan, using a medical CT scanner (slice thickness of $0.625 \mathrm{~mm}$ ). From these CTscans, 3D virtual objects of each of the skeletal elements of the trunk (vertebrae, ribs, manubrium and mesosternum) as well of the pelvis were created using Avizo (v. AvizoLite).

3D virtual reconstruction. The virtual reconstruction of the thorax was based upon a slightly modified 3D reconstruction of the spine of this individual (Supplementary Note 2) to which the ribs and the sternal elements were added using Avizo (v. AvizoLite). Coxal bones were added to provide a context for the thorax reconstruction.

The ribs of Kebara 2 individual suffer from both taphonomic deformation and error in initial reconstruction. A careful assessment of all the original vertebrae and ribs was performed in order to select the best-preserved ribs and to compensate for potential taphonomic/reconstruction problems. In some cases, mirror-imaging of the skeletal elements was necessary due to taphonomic, reconstruction, and/or preservation concerns (Supplementary Note 2).

Traditional and geometric morphometric analysis. The morphometric analysis of the $3 \mathrm{D}$ reconstructed thorax was performed using both traditional and geometric morphometric (GMM) analyses. For both the traditional and the GMM analyses, the K2 reconstructed thorax was compared to a sample of medical scans comprising 16 adult modern male thoraxes: 10 of them were scanned for post-mortem autopsy and six were patients at the Ziv Medical Center, Faculty of Medicine, Bar Ilan University (Safed). All individuals were scanned in supine position and we avoided CT-scanning individuals with significant morphological deformations and/ or causes of death that might have altered ribcage morphology. Prior to analysis, all CT-data were anonymized to comply with the Helsinki declaration ${ }^{66,67}$. Despite the differences in age (or age-at-death) between $\mathrm{K} 2$ and this modern human sample (Table 1), we consider this comparative sample to be representative of modern adult males, because a comparison of this sample to that of another adult modern male sample ${ }^{50}(n=18$; age $=51.9 \pm 1.2$ years $)$ using a landmark protocol of 402 landmarks (ribs 1-10) did not yield statistical differences between the samples (permutation test; $n=100 ; p=0.14$ ). The traditional morphometric analysis consisted of: (a) the direct comparison of the morphology of the thorax between our reconstruction and modern humans and (b) the comparison of selected measurements between the $\mathrm{K} 2$ reconstruction and the modern human comparison sample (Table 1). For the GMM analysis we digitized 526 3D landmarks and semilandmarks on each ribcage using Viewbox 4 software (www.dhal.com), based on a recently published protocol for quantifying the ribcage of hominoids ${ }^{68}$. Additionally, a metric analysis of selected linear measurements of T1-T10 vertebrae was performed using a different comparative sample (Supplementary Note 1).

To assess the size and shape of the thorax using GMM, for ribs 1-10, 20 landmarks ( 7 fixed and 13 sliding); in ribs 11-12, 19 landmarks (6 fixed and 13 sliding) were captured in each rib, and four fixed landmarks at each thoracic vertebra $^{68}$. For ribs 1-10, fixed landmarks at the rib head were digitized at the most superior and most inferior points with another landmark at the most medial point of the rib head at the inter-articular crest. One additional landmark was placed at the most lateral point of the articular tubercle, and on the shaft, one landmark was placed at the most inferior point at the posterior angle and one each at the most superior and most inferior points of sternal ends. On the 11th and 12th ribs, only six fixed landmarks were collected due to the absence of the inter-articular crest at the rib head. Thirteen equidistant semilandmarks were placed along the lower costal border between the articular tubercle and the inferior sternal end. Additionally, four landmarks were placed at each of the thoracic vertebrae (T1-T12): most antero-superior and most antero-inferior points on the vertebral body at the midline and the most superior and most inferior points at the lower part of the spinous processes. Semilandmarks were slid twice, the first time to the template during digitizing and a second time to the sample average following standard sliding protocol ${ }^{23,69,70}$.

In the case of the K2 thorax, we needed to estimate the missing landmarks, mainly at several proximal and distal ends due to the preservation of the fossils (Fig. 1, Supplementary Note 2). Those landmarks were estimated following reference-based estimation through a thin-plate spline (TPS) method ${ }^{71}$. According 
to this method, the coordinates of the reference individual, where all landmarks and semilandmarks are present, is used to calculate the missing data of the target specimen through an interpolation function using the reference information, so that the bending energy is minimized ${ }^{71}$. In order to be conservative and due to the lack of other Neandertal rib cages to use as references, we used the coordinates of the mean $H$. sapiens male thorax as a reference specimen. Average $H$. sapiens coordinates were calculated using MorphoJ software ${ }^{72}$. The semilandmarks were slid twice and the full set of 3D coordinates was subjected to a generalized Procrustes analysis ${ }^{44}$. Size was quantified as centroid size (CS) defined as the square root of the summed squared distances of each landmark to the centroid, with the centroid of a configuration calculated as the average coordinate $(x, y, z)$ of the whole set of coordinates ${ }^{44,73}$. Morphological variability of the sample was explored by principal component analyses in shape space and form space ${ }^{74}$ using EVAN toolkit software. Mean comparisons were also carried out between K2 and modern human males using a permutation test ( $n=1000$ permutations) in MorphoJ software ${ }^{72}$.

\section{Data availability}

Kebara 2 original fossils are accessible with permission of Israel Hershkowitz. The 3D models of the spine and thorax reconstruction of Kebara 2 are available from the corresponding author upon request and in figshare with the identifier https://doi.org/ 10.6084/m9.figshare.7012256

Received: 12 May 2018 Accepted: 17 September 2018

Published online: 30 October 2018

\section{References}

1. Kapandji, I. A. The Physiology of the joints. Vol. 3: The Trunk and Vertebral Column (Churchill Livingstone, Edinburgh, 1974).

2. Stahl, W. R. Scaling of respiratory variables in mammals. J. Appl. Physiol. 22, 453-460 (1967).

3. Bellemare, J.-F., Cordeau, M.-P., Leblanc, P. \& Bellemare, F. Thoracic dimensions at maximum lung inflation in normal subjects and in patients with obstructive and restrictive lung diseases. Chest 119, 376-386 (2001).

4. Churchill, S. E. in Neanderthals Revisited: New Approaches and Perspectives (eds Harvati, K. \& Harrison, T.) 113-134 (Springer, Amsterdam, 2006).

5. Preuschoft, H. Mechanisms for the acquisition of habitual bipedality: are there biomechanical reasons for the acquisition of upright bipedal posture? J. Anat. 204, 363-384 (2004).

6. Been, E., Gómez-Olivencia, A., Kramer, P. A. \& Barash, A. in Human Paleontology and Prehistory: Contributions in Honor of Yoel Rak (Springer, Cham, 2017).

7. Been, E. et al. Evolution of spinopelvic alignment in Hominins. Anat. Rec. 300, 900-911 (2017).

8. Franciscus, R. G. \& Churchill, S. E. The costal skeleton of Shanidar 3 and a reappraisal of Neandertal thoracic morphology. J. Hum. Evol. 42, 303-356 (2002).

9. Gómez-Olivencia, A., Eaves-Johnson, K. L., Franciscus, R. G., Carretero, J. M. \& Arsuaga, J. L. Kebara 2: new insights regarding the most complete Neandertal thorax. J. Hum. Evol. 57, 75-90 (2009).

10. García-Martínez, D. et al. On the chest size of Kebara 2. J. Hum. Evol. 70, 69-72 (2014)

11. Fuhlrott, C. Mensliche Ueberreste aus einer Felsengrotte des Düsselthals. Verh. Des. Nat. Ver. 60, 131-153 (1859).

12. Fraipont, J. \& Lohest, M. La race humaine de Néanderthal ou de Canstadt en Belgique. Arch. Biol. 7, 587-757 (1887).

13. Gorjanović-Kramberger, K. Der diluviale Mensch von Krapina (C.W. Kreidel's verlag, Wiesbaden, 1906).

14. Boule, M. L'homme fossile de la Chapelle aux Saints. Ann. De. Paléontol. 6, 111-172 (1911).

15. Churchill, S. E. Medial clavicular length and upper thoracic shape in Neandertals and European early modern humans. Am. J. Phys. Anthropol. S18, 67-68 (1994).

16. McCown, T. D. \& Keith, A. The stone age of Mount Carmel. The Fossil Human Remains from the levalloiso-mousterian (Clarendon Press, Oxford, 1939).

17. Arensburg, B. in Le squelette moustérien de Kébara 2 (eds Bar-Yosef, O. \& Vandermeersch, B.) 113-147 (Éditions du CNRS, Paris, 1991).

18. Trinkaus, E. The Shanidar Neandertals (Academic Press, New York, 1983).

19. Gómez-Olivencia, A. The costal skeleton of the Neandertal individual of La Chapelle-aux-Saints 1. Ann. Paléontol. 101, 127-141 (2015).

20. Bastir, M. et al. The relevance of the first ribs of the El Sidrón site (Asturias, Spain) for the understanding of the Neandertal thorax. J. Hum. Evol. 80, 64-73 (2015).
21. García-Martínez, D. et al. The costal remains of the El Sidrón Neanderthal site (Asturias, northern Spain) and their importance for understanding Neanderthal thorax morphology. J. Hum. Evol. 111, 85-101 (2017).

22. Gómez-Olivencia, A., Holliday, T., Madelaine, S., Couture-Veschambre, C. \& Maureille, B. The costal skeleton of the Regourdou 1 Neandertal. J. Hum. Evol. https://doi.org/10.1016/j.jhevol.2017.12.005 (2018).

23. Bastir, M. et al. Differential growth and development of the upper and lower human thorax. PLoS ONE 8, e75128 (2013).

24. Froehle, A. W. \& Churchill, S. E. Energetic competition between neandertals and anatomically modern humans. PaleoAnthropology 2009, 96-116 (2009).

25. Gómez-Olivencia, A., Franciscus, R. G., Couture-Veschambre, C., Maureille, B. \& Arsuaga, J. L. The mesosternum of the Regourdou 1 Neandertal revisited. J. Hum. Evol. 62, 511-519 (2012).

26. Bastir, M. et al. Three-dimensional morphometrics of thoracic vertebrae in Neandertals and the fossil evidence from El Sidrón (Asturias, Northern Spain). J. Hum. Evol. 108, 47-61 (2017).

27. Sawyer, G. J. \& Maley, B. Neanderthal reconstructed. Anat. Rec. 283B, 23-31 (2005).

28. Been, E., Gómez-Olivencia, A. \& Kramer, P. A. Lumbar lordosis of extinct hominins. Am. J. Phys. Anthropol. 147, 64-77 (2012).

29. Been, E., Gómez-Olivencia, A. \& Kramer, P. A. Brief Communication: Lumbar lordosis in extinct hominins: Implications of the pelvic incidence. Am. J. Phys. Anthropol. 154, 307-314 (2014).

30. Gómez-Olivencia, A., Been, E., Arsuaga, J. L. \& Stock, J. T. The Neandertal vertebral column 1: The cervical spine. J. Hum. Evol. 64, 608-630 (2013b).

31. Gómez-Olivencia, A., Arlegi, M., Barash, A., Stock, J. T. \& Been, E. The Neandertal vertebral column 2: The lumbar spine. J. Hum. Evol. 106, 84-101 (2017).

32. Bar-Yosef, O. in Le squelette moustérien de Kébara 2 (eds Bar-Yosef, O. \& Vandermeersch, B.) 17-27 (Éditions du CNRS, Paris, 1991).

33. Smith, P. \& Arensburg, B. A mousterian skeleton from Kebara cave. Eretz-Isr 13, 164-176 (1977).

34. Bar-Yosef, O. \& Vandermeersch, B. Le Squelette Moustérien de Kébara 2 (Éditions du CNRS, Paris, 1991).

35. Tillier, A.-M., Arensburg, B., Vandermeersch, B. \& Chech, M. New human remains from Kebara Cave (Mount Carmel). The place of the Kebara hominids in the Levantine Mousterian fossil record. Paléorient 29, 35-62 (2003).

36. Arensburg, B. et al. Une sépulture néandertalienne dans la grotte de Kébara (Isräl). C. R. Acad. Sci. Paris 300, 227-230 (1985).

37. Valladas, H. \& Valladas, G. in Le squelette moustérien de Kébara 2 (eds Bar-Yosef, O. \& Vandermeersch, B.) 43-47 (Éditions du CNRS, Paris, 1991).

38. Karasik, D., Arensburg, B., Tillier, A. M. \& Pavlovsky, O. M. Skeletal age assessment of fossil hominids. J. Archaeol. Sci. 25, 689-696 (1998).

39. Rak, Y. On the differences between two pelvises of Mousterian context from the Qafzeh and Kebara caves, Israel. Am. J. Phys. Anthropol. 81, 323-332 (1990).

40. Carretero, J. M. et al. Stature estimation from complete long bones in the Middle Pleistocene humans from the Sima de los Huesos, Sierra de Atapuerca (Spain). J. Hum. Evol. 62, 242-255 (2012).

41. Ruff, C. B., Trinkaus, E. \& Holliday, T. W. Body mass and encephalization in Pleistocene Homo. Nature 387, 173-176 (1997).

42. Duday, H. \& Arensburg, B. in Le squelette moustérien de Kébara 2 (eds BarYosef, O. \& Vandermeersch, B.) 180-193 (Éditions du CNRS, Paris, 1991).

43. García-Martínez, D. et al. Reevaluation of "endocostal ossifications" on the Kebara 2 Neanderthal ribs. J. Hum. Evol. 122, 33-37 (2018).

44. Zelditch, M., Swiderski, D. \& Sheets, H. Geometric Morphometrics for Biologists 2nd edn (Academic Press, 2012).

45. Tague Robert, G. Sexual dimorphism in the human bony pelvis, with a consideration of the Neandertal pelvis from Kebara cave, Israel. Am. J. Phys. Anthropol. 88, 1-21 (1992).

46. Weaver, T. D. \& Hublin, J.-J. Neandertal birth canal shape and the evolution of human childbirth. Proc. Natl Acad. Sci. USA 106, 8151-8156 (2009).

47. Beyer, B. et al. In vivo thorax $3 \mathrm{D}$ modelling from costovertebral joint complex kinematics. Clin. Biomech. 29, 434-438 (2014).

48. Bastir, M. et al. In vivo 3D analysis of thoracic kinematics: changes in size and shape during breathing and their implications for respiratory function in recent humans and fossil Hominins. Anat. Rec. 300, 255-264 (2017).

49. García-Martínez, D. et al. Ribcage measurements indicate greater lung capacity in Neanderthals and Lower Pleistocene hominids compared to modern humans. Comm. Biol.1, 117 (2018).

50. García-Martínez, D., Torres-Tamayo, N., Torres-Sanchez, I., García-Río, F. \& Bastir, M. Morphological and functional implications of sexual dimorphism in the human skeletal thorax. Am. J. Phys. Anthropol. 161, 467-477 (2016).

51. Beall, C. M. Adaptations to altitude: a current assessment. Ann. Rev. Anthropol. 30, 423-456 (2001). 
52. Rak, Y. \& Arensburg, B. Kebara 2 Neanderthal pelvis: first look at a complete inlet. Am. J. Phys. Anthropol. 73, 227-231 (1987).

53. Bonmatí, A. et al. Middle Pleistocene lower back and pelvis from an aged human individual from the Sima de los Huesos site, Spain. Proc. Natl Acad. Sci. USA 107, 18386-18391 (2010).

54. Been, E., Peleg, S., Marom, A. \& Barash, A. Morphology and function of the lumbar spine of the Kebara 2 Neandertal. Am. J. Phys. Anthropol. 142, 549-557 (2010).

55. Torres-Tamayo, N. et al. The torso integration hypothesis revisited in Homo sapiens: Contributions to the understanding of hominin body shape evolution. Am. J. Phys. Anthropol. https://doi.org/10.1002/ajpa.23705 (2018).

56. Arsuaga, J. L. et al. A complete human pelvis from the Middle Pleistocene of Spain. Nature 399, 255-258 (1999).

57. Carretero, J. M. et al. in Miscelánea en Homenaje a Emiliano Aguirre. Volumen III. Paleoantropología (E. Baquedano \& S. Rubio eds) 120-135 (Museo arqueológico regional, Alcalá de. Henares, 2004).

58. Simpson, S. W. et al. A female Homo erectus pelvis from Gona, Ethiopia. Science 322, 1089-1092 (2008).

59. Arsuaga, J. L. Terrestrial apes and phylogenetic trees. Proc. Natl Acad. Sci. USA 107, 8910-8917 (2010).

60. Gómez-Olivencia, A., Couture-Veschambre, C., Madelaine, S. \& Maureille, B. The vertebral column of the Regourdou 1 Neandertal. J. Hum. Evol. 64, 582-607 (2013).

61. Arsuaga, J. L. et al. Postcranial morphology of the middle Pleistocene humans from Sima de los Huesos, Spain. Proc. Natl Acad. Sci. USA 112, 11524-11529 (2015).

62. Gómez-Olivencia, A. et al. The costal skeleton of Homo antecessor: preliminary results. J. Hum. Evol. 59, 620-640 (2010).

63. Arsuaga, J. L. et al. Neandertal roots: cranial and chronological evidence from Sima de los Huesos. Science 344, 1358-1363 (2014).

64. Brown, F. H., Harris, J., Leakey, R. \& Walker, A. Early Homo erectus skeleton from West Lake Turkana, Kenya. Nature 316, 788-792 (1985).

65. Jellema, L. M., Latimer, B. \& Walker, A. in The Nariokotome Homo erectus skeleton (eds Walker, A. \& Leakey, R. eds) 294-325 (Harvard University Press, Cambridge, 1993).

66. Schmid, P. et al. Mosaic morphology in the thorax of Australopithecus sediba. Science 340, 1234598 (2013).

67. Goodyear, M. D. E., Krleza-Jeric, K. \& Lemmens, T. The declaration of Helsinki. BMJ 335, 624-625 (2007).

68. Bastir, M. et al. 3D geometric morphometrics of thorax variation and allometry in Hominoidea. J. Hum. Evol. 113, 10-23 (2017).

69. Mitteroecker, P. \& Gunz, P. Advances in geometric morphometrics. Evol. Biol. 36, 235-247 (2009).

70. Gunz, P. \& Mitteroecker, P. Semilandmarks: a method for quantifying curves and surfaces. Hystrix, Ital. J. Mammal. 24, 103-109 (2013).

71. Gunz, P., Mitteroecker, P., Neubauer, S., Weber, G. W. \& Bookstein, F. L. Principles for the virtual reconstruction of hominin crania. J. Hum. Evol. 57, 48-62 (2009).

72. Klingenberg Christian, P. MorphoJ: an integrated software package for geometric morphometrics. Mol. Ecol. Resour. 11, 353-357 (2011).

73. O'Higgins, P. The study of morphological variation in the hominid fossil record: biology, landmarks and geometry. J. Anat. 197, 103-120 (2000).

74. Dryden, I. L. \& Mardia, K. V. Statistical Shape Analysis (Wiley, Chichester, 1998).

75. Sjøvold, T. Estimation of stature from long bones utilizing the line of organic correlation. Hum. Evol. 5, 431-447 (1990).
76. Vandermeersch, B. in Le squelette moustérien de Kébara 2 (eds Bar-Yosef, O. \& Vandermeersch, B.) 157-178 (Éditions du CNRS, Paris, 1991).

\section{Acknowledgements}

We thank the excavation and research team of Kebara for their work that has allowed for the recovery of the Kebara 2 individual and B. Arensburg, Y. Rak, B. Vandermeersch, O. Bar-Yosef and I. Hershkowitz their permission to study the K2 specimen and V. Slon for technical help. Thanks to our colleagues from MNHN, TAU, EHU-UPV, MNCN, UCM-ISCIII, UCAM, and especially A. Balzeau, J. Stock, C. Shaw,

T. Holliday, R.G. Franciscus, T. Durden, J.L. Arsuaga, and J.M. Carretero for their support and constructive discussion. We thank J. Trueba and Madrid Scientific Films for letting us to use one of their photographs. A.G.-O. had a Marie Curie-IEF (FP7-PEOPLE2012-IEF 327243) research fellowship during part of this work. A.G.-O. and M.A. received support from the Spanish Ministerio de Ciencia y Tecnología (Project: CGL-2015-65387-C3-2-P, MINECO/FEDER) and are also part of the Research Group IT1044-16 from the Eusko Jaurlaritza-Gobierno Vasco and Group PPG17/05 from the Universidad del País Vasco-Euskal Herriko Unibertsitatea (UPV/EHU). D.G.-M. and M.B. received support from the Ministerio de Ciencia y Tecnología (Project: CGL2015-63648-P).

\section{Author contributions}

A.G.-O. and E.B. designed research; A.G.-O., A.B., D.G.-M., M.A., P.K., M.B. and E.B. performed research; A.G.-O., A.B., D.G.-M., M.A., P.K., M.B. and E.B. analyzed data; A.G.-O., A.B., D.G.-M., M.A., P.K., M.B. and E.B. wrote the paper.

\section{Additional information}

Supplementary Information accompanies this paper at https://doi.org/10.1038/s41467018-06803-z.

Competing interests: The authors declare no competing interests.

Reprints and permission information is available online at http://npg.nature.com/ reprintsandpermissions/

Publisher's note: Springer Nature remains neutral with regard to jurisdictional claims in published maps and institutional affiliations.

(c) (i) Open Access This article is licensed under a Creative Commons Ay Attribution 4.0 International License, which permits use, sharing adaptation, distribution and reproduction in any medium or format, as long as you give appropriate credit to the original author(s) and the source, provide a link to the Creative Commons license, and indicate if changes were made. The images or other third party material in this article are included in the article's Creative Commons license, unless indicated otherwise in a credit line to the material. If material is not included in the article's Creative Commons license and your intended use is not permitted by statutory regulation or exceeds the permitted use, you will need to obtain permission directly from the copyright holder. To view a copy of this license, visit http://creativecommons.org/ licenses/by/4.0/.

(C) The Author(s) 2018 